ARTICLE

https://doi.org/10.1038/s41467-021-24596-6

\title{
Organozinc pivalates for cobalt-catalyzed difluoroalkylarylation of alkenes
}

\author{
Xinyi Cheng ${ }^{1,3}$, Xingchen Liu ${ }^{1,3}$, Shengchun Wang ${ }^{2,3}$, Ying $\mathrm{Hu}^{1}$, Binjing $\mathrm{Hu}^{1}$, Aiwen Lei ${ }^{2 凶} \& \mathrm{Jie}^{\mathrm{Li}} \mathrm{i}^{1 凶}$
}

Installation of fluorine into pharmaceutically relevant molecules plays a vital role in their properties of biology or medicinal chemistry. Direct difunctionalization of alkenes and 1,3dienes to achieve fluorinated compounds through transition-metal catalysis is challenging, due to the facile $\beta-\mathrm{H}$ elimination from the $\mathrm{Csp}^{3}-[\mathrm{M}]$ intermediate. Here we report a cobaltcatalyzed regioselective difluoroalkylarylation of both activated and unactivated alkenes with solid arylzinc pivalates and difluoroalkyl bromides through a cascade $\mathrm{Csp}^{3}-\mathrm{Csp}^{3} / \mathrm{Csp}^{3}-\mathrm{Csp}^{2}$ bond formation under mild reaction conditions. Indeed, a wide range of functional groups on difluoroalkyl bromides, olefins, 1,3-dienes as well as (hetero)arylzinc pivalates are well tolerated by the cobalt-catalyst, thus furnishing three-component coupling products in good yields and with high regio- and diastereoselectivity. Kinetic experiments comparing arylzinc pivalates and conventional arylzinc halides highlight the unique reactivity of these organozinc pivalates. Mechanistic studies strongly support that the reaction involves direct halogen atom abstraction via single electron transfer to difluoroalkyl bromides from the in situ formed cobalt(I) species, thus realizing a $\mathrm{Co}(\mathrm{I}) / \mathrm{Co}(\mathrm{II}) / \mathrm{Co}(\mathrm{III})$ catalytic cycle.

\footnotetext{
${ }^{1}$ Key Laboratory of Organic Synthesis of Jiangsu Province, College of Chemistry, Chemical Engineering and Materials Science, Soochow University, Suzhou, People's Republic of China. ${ }^{2}$ College of Chemistry and Molecular Sciences, the Institute for Advanced Studies (IAS), Wuhan University, Wuhan, People's Republic of China. ${ }^{3}$ These authors contributed equally: Xinyi Cheng, Xingchen Liu, Shengchun Wang. ${ }^{凶}$ email: aiwenlei@whu.edu.cn; jjackli@suda.edu.cn
} 
$\mathrm{O}$ rganometallic reagents, due to their versatile reactivity and high functional group compatibility, have been broadly used for the synthesis of pharmaceuticals and agrochemicals. Especially, transition metal-catalyzed cross-coupling strategy, is of great importance for the development of modern organic chemistry ${ }^{1-6}$. Among them, boron ${ }^{7-10}$ and zinc organometallics $^{11-15}$ have found extensive applications in such coupling reactions for the preparation of a wide range of highly complex molecules. As compared with the bench-stable, commercially available boronic derivatives, conventional organozinc reagents $(\mathrm{RZnX}, \mathrm{X}=\mathrm{Cl}, \mathrm{Br}, \mathrm{I})$ displayed even more exquisite reactivity under mild reaction conditions in many coupling reactions; however, highly air- and moisture-sensitive still represent drawbacks for their synthetic applications. Remarkably, Knochel and coworkers recently developed a solid organozinc pivalate $\left(\mathrm{RZnX} \cdot \mathrm{Mg}(\mathrm{OPiv})_{2} \cdot \mathrm{LiCl}\right.$, which is abbreviated henceforth as RZnOPiv for the sake of clarity ${ }^{16}$, which shows greatly enhanced air and moisture stability after solvent evaporation ${ }^{17}$. These organozinc reagents, including (hetero)aryl ${ }^{17-22}$, alkynyl $^{23,24}$, and alkyl zinc pivalates ${ }^{25}$, exhibited good reactivity in Pd-catalyzed cross-coupling reactions with unsaturated halides, which further proved to be broadly applicable for the late-stage functionalizations of biologically active molecules ${ }^{26}$. Although palladium catalysts are very useful, the $3 \mathrm{~d}$ transition metals $^{27-34}$, especially cobalt ${ }^{35-39}$, have recently found numerous applications due to its low toxicity, low cost, and natural abundance. Recently, (hetero)arylzinc pivalates have been successfully used for cobalt-catalyzed cross-couplings with unsaturated halides ${ }^{40}$, alkenyl acetates $^{41}$, N-hydroxylamine benzoates ${ }^{42}$, anthranils ${ }^{43}$, N-hydroxyphthalimide ${ }^{44}$, as well as thiopyridyl ester derivatives ${ }^{45}$. Therefore, the ease of preparation, stability, and exquisite reactivity of these solid zinc reagents have attracted considerable attention of synthetic chemists.

Transition-metal-catalyzed regioselective difunctionalizations of olefins with two different functional groups have been recognized as an increasingly viable tool for preparing complex organic compounds from readily available starting materials ${ }^{46-48}$. However, due to the facile $\beta-\mathrm{H}$ elimination from the $\mathrm{Csp}^{3}-[\mathrm{M}]$ intermediate ${ }^{49-52}$, it still remained challenging to construct two $\mathrm{C}-\mathrm{C}$ bonds through transition-metal catalyzed multicomponent dicarbofunctionalization of alkenes (Fig. 1a) ${ }^{53-55}$. Importantly, highly regioselective $\mathrm{Ni}$ catalyzed alkylarylation of vinylarenes with alkyl halides and arylzinc iodides has been recently developed by Giri and coworkers ${ }^{56}$, they further extended the substrate scope to a-halocarbonyl derivatives (Fig. 1a $)^{57}$. Besides, the installation of fluorine into bioactive molecules uniquely plays a vital role in their properties of relevance to biology or medicinal chemistry ${ }^{58-63}$, although major advances in transition-metal-catalyzed fluoroalkylation have been achieved in recent years ${ }^{64-68}$. It is worth noting that the elegant Ni-catalyzed tandem difluoroalkylation-(alkyl)arylation of enamides to the synthesis of difluoroalkylated amides was illustrated by Zhang and coworkers ${ }^{69-71}$. To the best of our knowledge, organozinc reagents for transition-metal-catalyzed difunctionalization of alkenes and 1,3dienes to achieve fluorinated compounds were rather rare and limited to the use of nickel catalysis with activated alkenes ${ }^{71}$. In particular, the much less toxic and industrial-friendly cobalt catalysts have unfortunately thus far proven elusive for the aforementioned three-component cascade coupling reactions ${ }^{72,73}$.

Recently, our laboratory reported the fluorine installation through cobalt- ${ }^{74}$ and copper-catalyzed ${ }^{75}$ alkyne and alkene difunctionalization strategies. In this work, we report a versatile cobalt-catalyzed regioselective difluoroalkylarylation of (un)activated alkenes and 1,3-dienes with polyfunctionalized arylzinc pivalates and difluoroalkyl bromides (Fig. 1b), which provides an expedient method to install fluorine into complex compounds. Of special interest in this cobalt catalysis is that the arylzinc pivalates seem very crucial for promoting the overall catalytic efficacy.

\section{Results}

We initiated our studies by optimizing reaction conditions for the envisioned cobalt-catalyzed regioselective three-component coupling of alkenylarene (2a) with bromodifluoroacetate (1a) and phenylzinc pivalate (3a, PhZnOPiv). A cascade cross-coupling reaction was observed in the presence of $10.0 \mathrm{~mol}^{\circ} \mathrm{CoBr}_{2}$ under ligand-free conditions, thus affording the desired aryldifluoroalkylated product 4 in $83 \%$ yield with high regioselectivity (Fig. 2a, entry 1). Among a number of representative chelating ligands, bipyridines have given negative effects, and only a trace amount of product was observed (entries 2-3); tridentate 2,6-bis( $N$-pyrazolyl)pyridine, 1,10-phenanthrolines, diimine, TMEDA, $\mathrm{ME}_{4} \mathrm{DACH}$, as well as dppbz ligands gave poor-to-high yields, whereas the neocuproine (L5) afforded $\mathbf{4}$ in $92 \%$ (entries 4-10). Further, testing reactions with different solvents verified the crucial importance of $\mathrm{MeCN}$ as the reaction medium (entry 11; see SI). Switching from $\mathrm{CoBr}_{2}$ to other representative cobalt salts, such as $\mathrm{CoCl}_{2}$ and $\mathrm{CoCl}_{2}\left(\mathrm{PPh}_{3}\right)_{2}$, led to significant reduced yields (entry 12-13). In sharp contrast, replacement of $\mathrm{CoBr}_{2}$ by using $\mathrm{NiBr}_{2}, \mathrm{FeCl}_{2}, \mathrm{CrCl}_{2}$, or $\mathrm{CuBr}$ failed to furnish the desired product 4 (entry 14).

Lei $^{76-78}$ demonstrated that arylzinc reagents prepared by different methods possess very different kinetics in palladium- and nickel-catalyzed oxidative couplings, and further X-ray absorption spectroscopy studies show that changing the halide anion from $\mathrm{Cl}$ to $\mathrm{Br}$ or I will result in an increase of the $\mathrm{Zn}-\mathrm{C}$ bond distance and thereby improve the trans-metalation rate ${ }^{79}$. In order to preliminarily reveal the different kinetics between this solid zinc reagent and conventional zinc reagents, a series of control experiments with six different phenylzinc reagents, which prepared by transmetallation of the corresponding phenylmagnesium halides and zinc halides (Note: PhZnOPiv was prepared from $\mathrm{PhMgCl}$ and $\mathrm{Zn}(\mathrm{OPiv}) 2$ with 1:1.2 ratio; $\mathrm{Ph} 2 \mathrm{Zn}$ $2 \mathrm{Mg}$ (OPiv)Cl was prepared from $\mathrm{PhMgCl}$ and $\mathrm{Zn}(\mathrm{OPiv}) 2$ with 2:1 ratio; $\mathrm{PhZnX}$ was prepared from $\mathrm{PhMgX}$ and $\mathrm{ZnX} 2$ with 1:1.2 ratio; $\mathrm{Ph} 2 \mathrm{Zn} \cdot 2 \mathrm{MgCl} 2$ was prepared from $\mathrm{PhMgCl}$ and $\mathrm{ZnCl} 2$ with 2:1 ratio), were also performed under the ligand-free cobalt catalysis (Fig. 2b). Interestingly, all of these reactions were almost finished within remarkably short reaction times of only $15 \mathrm{~min}$. It is worth noting that significantly reduced conversions of $\mathbf{4}$ were observed when using $\mathrm{PhZnX}\left(\mathrm{X}=\mathrm{Cl}, \mathrm{Br}\right.$, or I), $\mathrm{Ph}_{2} \mathrm{Zn} \cdot 2 \mathrm{MgCl}_{2}$, or $\mathrm{Ph}_{2} \mathrm{Zn} \cdot 2 \mathrm{Mg}(\mathrm{OPiv}) \mathrm{Cl}$ instead of PhZnOPiv. Moreover, the results of comparison experiments between $\mathrm{Ph}_{2} \mathrm{Zn} \cdot 2 \mathrm{Mg}(\mathrm{OPiv}) \mathrm{Cl}$ and $\mathrm{Ph}_{2} \mathrm{Zn} \cdot 2 \mathrm{MgCl}_{2}$ show the superiority of the former as well. Hence, these observations highlighted that the presence of $\mathrm{M}(\mathrm{OPiv})_{2}(\mathrm{M}$ $=\mathrm{Mg}$ or $\mathrm{Zn}$ ) has made these organozinc pivalates stand out among salt-supported organometallics, thus displaying the distinct advantage of reacting well in our regioselective cobaltcatalyzed difluoroalkylarylation of olefins.

Subsequently, the versatility of this optimized cobalt(II) catalyst was examined in a range of difluoroalkylarylation reactions with various polyfunctionalized arylzinc pivalates 3 (Fig. 3a). All arylzinc pivalates were prepared from the corresponding aryl halides by $\mathrm{Mg}$ insertion in the presence of $\mathrm{LiCl}^{80}$. Although the neocuproine (L5) gave the optimal results in the model reaction, in our efforts to extend the substrate scope of this domino reaction, ligand-free $\mathrm{CoBr}_{2}$ proved to be superior (see the results of products $7,9,11)$. A variety of para- and/or metal-substituted arylzinc pivalates were identified as viable nucleophiles for difluoroalkylarylation with bromodifluoroacetate (1a) and 4methoxystyrene (2a) to afford the desired products 4-16 in moderate yields. More sterically hindered 4-chloro-2- 
Previous work:

(a) Overview of alkene (di)functionalization with organometallic reagents

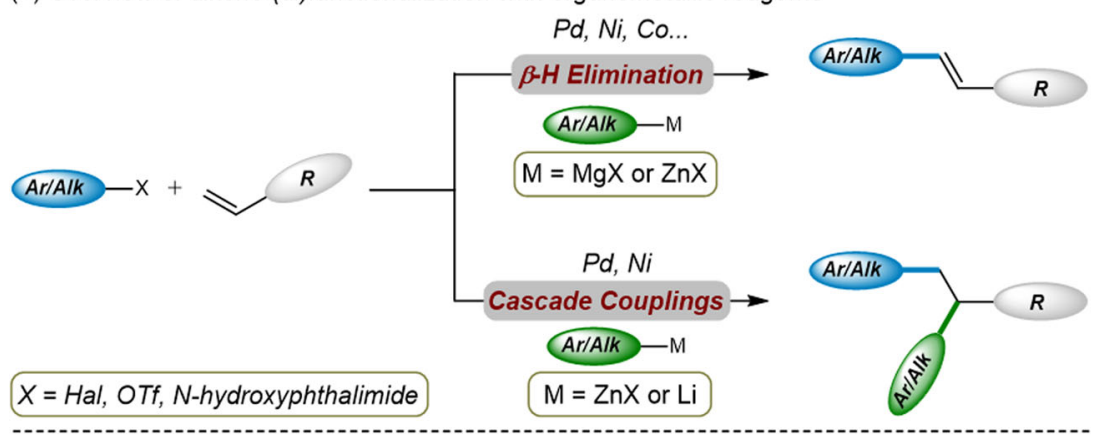

This work:

(b) Cobalt-catalyzed difluoroalkylarylative Negishi coupling
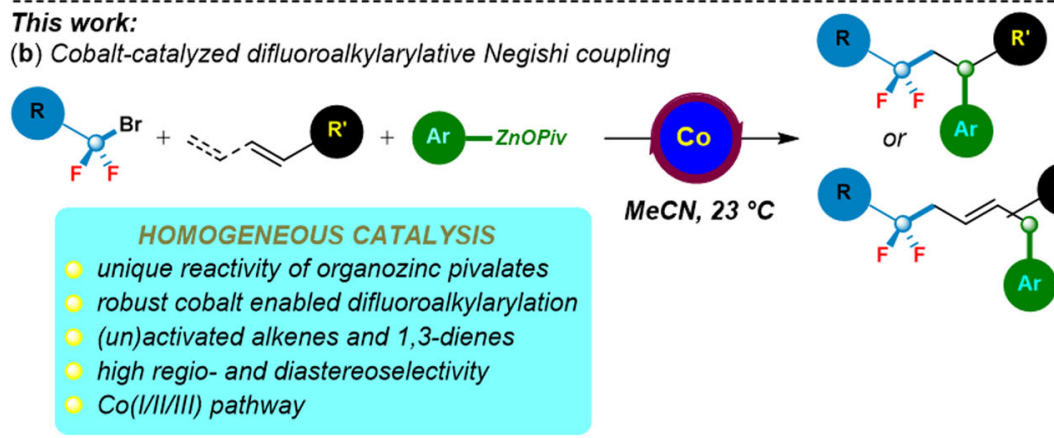

$\mathrm{MeCN}, 23^{\circ} \mathrm{C}$

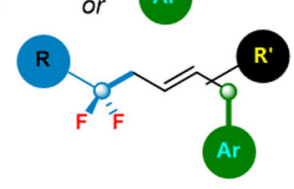

Fig. 1 Background and our objective. a Organometallic reagents for difunctionalization of olefins. b Organozinc pivalates for cobalt-catalyzed difluoroalkylarylation of olefins.

(a)

\begin{tabular}{ccc} 
Entry & Modified conditions & Yield $(\%)^{[\mathrm{b}]}$ \\
\hline $\mathbf{1}$ & no ligand & $\mathbf{8 3}$ \\
2 & $\mathrm{~L} 1$ instead of $\mathrm{L} 5$ & Trace \\
3 & $\mathrm{~L} 2$ instead of $\mathrm{L} 5$ & Trace \\
4 & $\mathrm{~L} 3$ instead of $\mathrm{L} 5$ & 62 \\
5 & $\mathrm{~L} 4$ instead of $\mathrm{L} 5$ & 16 \\
$\mathbf{6}$ & none & $\mathbf{9 2}$ \\
7 & $\mathrm{~L} 6$ instead of $\mathrm{L} 5$ & 80 \\
8 & $\mathrm{~L} 7$ instead of $\mathrm{L} 5$ & 53 \\
9 & $\mathrm{~L} 8$ instead of $\mathrm{L} 5$ & 51 \\
10 & $\mathrm{~L} 9$ instead of $\mathrm{L5}$ & 62 \\
11 & $\mathrm{THF}^{\mathrm{DMF}}$, or $\mathrm{NMP}$ instead of $\mathrm{MeCN}_{2}$ & $<12$ \\
12 & $\mathrm{CoCl}_{2}$ instead of $\mathrm{CoBr}$ & 49 \\
13 & $\mathrm{CoCl}_{2}\left(\mathrm{PPh}_{3}\right)_{2}$ instead of $\mathrm{CoBr}_{2}$ & 31 \\
14 & $\mathrm{NiBr}_{2}, \mathrm{FeCl}_{2}, \mathrm{CrCl}_{2}$, or $\mathrm{CuBr}$ instead of & Trace \\
& $\mathrm{CoBr}_{2}$ &
\end{tabular}

(b)

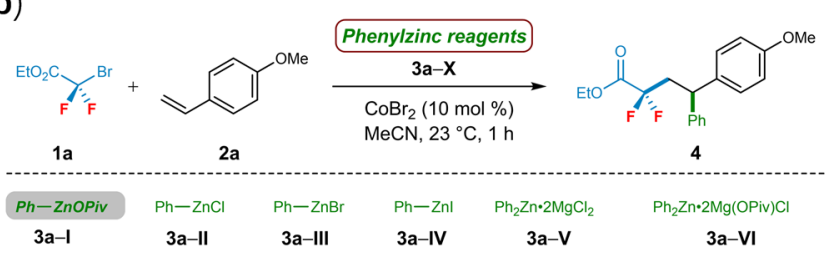

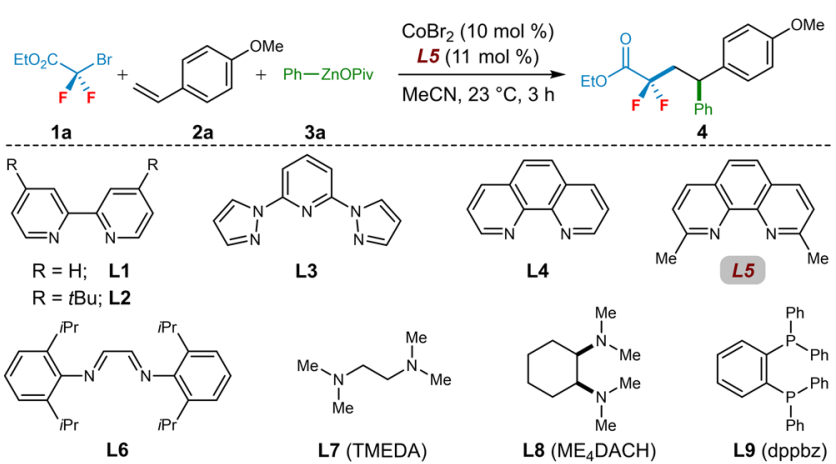

[a] Reaction conditions: 1a $(0.50 \mathrm{mmol}, 2.0$ equiv), $2 \mathrm{a}(0.25 \mathrm{mmol}, 1.0$ equiv), 3a $\left(0.50 \mathrm{mmol}, 2.0\right.$ equiv), $\mathrm{CoBr}_{2}(10 \mathrm{~mol} \%)$, L5 (11 $\left.\mathrm{mol} \%\right), \mathrm{MeCN}$ $(2.0 \mathrm{~mL}), 23 \mathrm{C}, 3 \mathrm{~h}$. [b] Isolated yields.

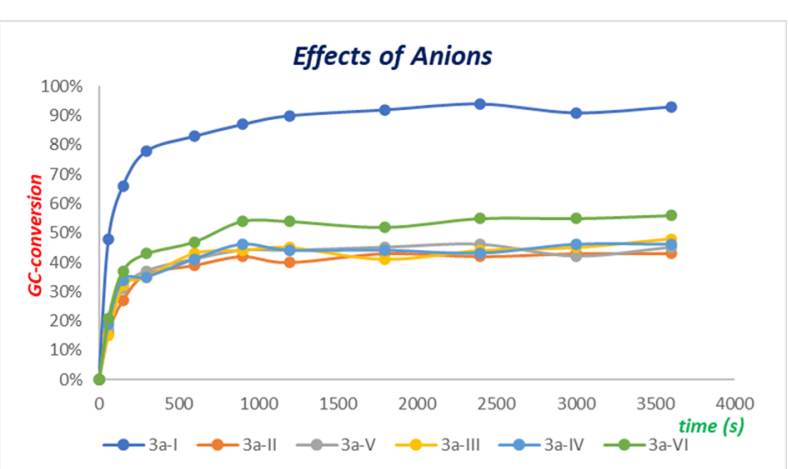

Fig. 2 Reaction optimization and reactivity of different arylzinc reagents. a Optimization for cobalt-catalyzed difluoroalkylarylation. b Kinetic experiments with different phenylzinc reagents of $3 a-X$. 


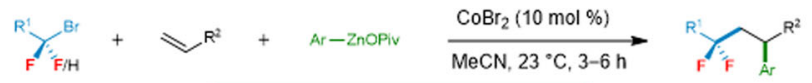

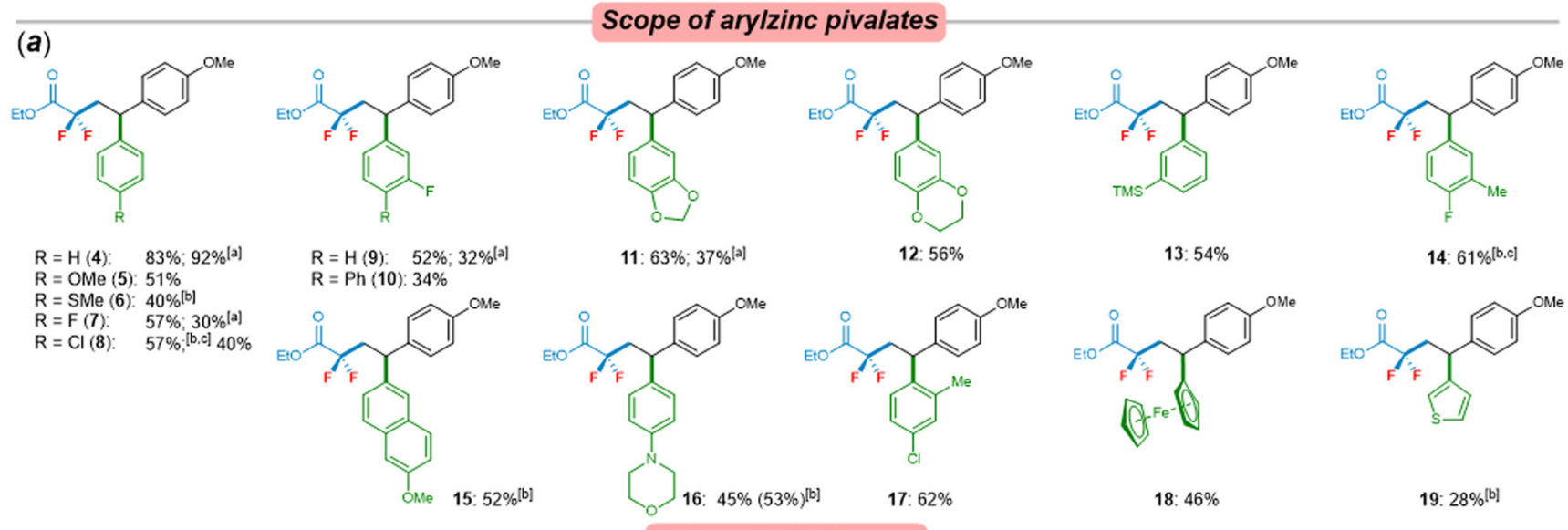

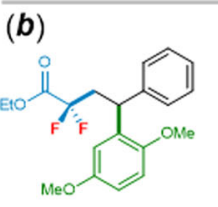

20: $91 \%$<smiles>O=C(O)CC(CC(F)(F)C(=O)O)c1ccc2c(c1)OCC2</smiles>

21: $57 \%$

Scope of vinylarenes<smiles>CC(C)(C)CCOc1ccc(C(CC(C)(C)C)c2ccccc2)cc1</smiles>

22: $78 \%$

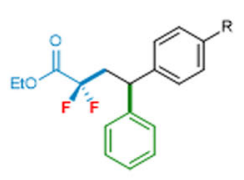

$$
R=F(23): 88 \%
$$
$\mathrm{R}=\mathrm{Cl}(24): 50 \%$ $\mathrm{R}=\mathrm{Cl}(24): 50 \%$
$\mathrm{R}=\mathrm{Br}(25): 76 \%$

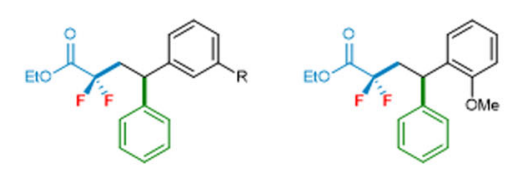

$$
\mathrm{R}=\mathrm{CF}_{3}(\mathbf{2 6}): 67 \%
$$
$\mathrm{R}=\mathrm{OMe}(27): 93 \%$

28: $62 \%$<smiles>CCOC(=O)C(F)(F)CC(c1ccccc1)c1ccc2ccccc2c1</smiles>

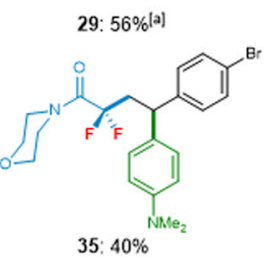

30: $55 \%$

31: $98 \%$

32: $64 \%$ Cl

$33: 52 \%$

39: $75 \%$

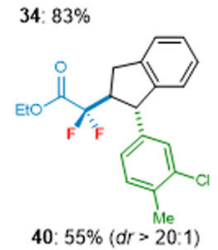

Scope of fluoroalkyl bromides

(c)<smiles>CC(C)C(C)C(C)Cc1ccc(N)cc1</smiles>

41: $34 \%(d r=1: 1)$<smiles>COc1ccc(C(CC(F)(F)c2nc3ccccc3o2)c2ccc(C(C)(C)C)cc2)cc1</smiles><smiles>CCCCCCCCCCCCCC(C)(C)C</smiles>

53: $24 \%\left(@ 35^{\circ} \mathrm{C}\right)$<smiles>CC(O)(CC(Cc1ccc(O)cc1)c1ccccc1)C(F)(F)F</smiles>

42: $97 \%$<smiles>Cc1ccc(C(CC(=O)O)c2ccc(CC(C)(C)C)cc2)cc1</smiles>

43: $53 \%$<smiles>O=C(O)CC(c1ccc(F)cc1)(c1ccc2c(c1)OCCO2)C(O)(F)F</smiles><smiles>CC1C(=O)c2ccccc2C(c2ccccc2)C1(C)C</smiles>

45: $51 \%(d r>20: 1)$<smiles>O=C(CC(F)(F)[C@H]1Cc2ccccc2[C@H]1c1ccccc1)O[Na]</smiles>

51: $41 \%(54 \%)^{[a]}$ $(d r>20: 1)$<smiles>[Y6]c1cc(OCCCC(CC(F)(F)C(=O)OCC)c2ccccc2)ccc1Cl</smiles><smiles>[R]OCC(C)(F)CC(c1ccccc1)c1ccc(F)cc1</smiles><smiles>COc1ccc(C(CC2CN(C(=O)OC(C)(C)C)C2)c2ccccc2)cc1</smiles>

54: $59 \%\left(@ 35^{\circ} \mathrm{C}\right)$

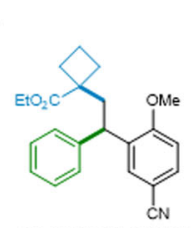

55: $31 \%\left(\right.$ @ $\left.35^{\circ} \mathrm{C}\right)$
$\mathrm{R}=\operatorname{Br}(50): \quad 72 \%$

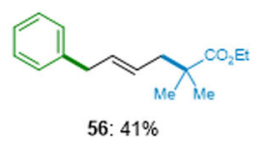

$(>93: 7 E: Z, r . r .>10: 1)$

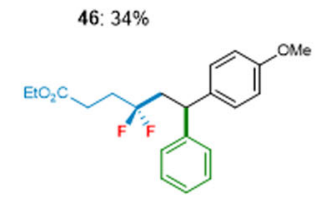

52: $53 \%\left[{ }^{[a]}\right.$

Fig. 3 Scope of cobalt-catalyzed cascade cross-coupling reaction. a Substrate scope of arylzinc pivalates. b Substrate scope of alkenylarenes and c fluoroalkyl bromides. Reaction conditions: alkyl bromides $(0.50 \mathrm{mmol}, 2.0$ equiv), alkenes $(0.25 \mathrm{mmol}, 1.0$ equiv), arylzinc pivalates ( $0.50 \mathrm{mmol}, 2.0$ equiv), $\mathrm{CoBr}_{2}(10 \mathrm{~mol} \%)$, and $\mathrm{MeCN}(2.0 \mathrm{~mL}), 23^{\circ} \mathrm{C}, 3-6 \mathrm{~h}$. [a] About $11 \mathrm{~mol} \%$ of $\mathbf{L} 5$ was used. [b] $\mathrm{CoBr}_{2}(20 \mathrm{mmol} \%)$ was used. [c] $\mathrm{Ar} \mathrm{Z}_{2} \mathrm{Zn} \cdot 2 \mathrm{Mg}(\mathrm{OPiv}) \mathrm{Cl}$ (2.0 equiv) was used. 


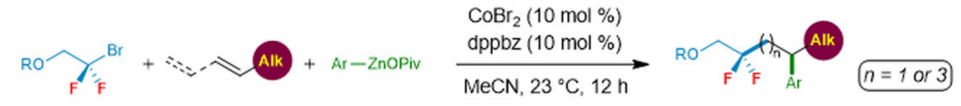

(a)

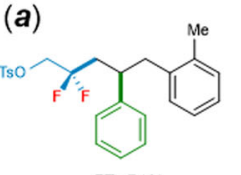

57: $51 \%$

(b)

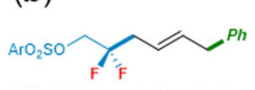

64: $80 \% \mathrm{Ar}=4-\mathrm{OMeC}_{6} \mathrm{H}_{4}$

$(>96: 4$ E:Z, r.r. $>10: 1)$
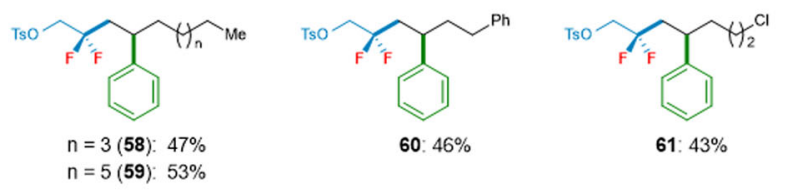

Tso

60: $46 \%$

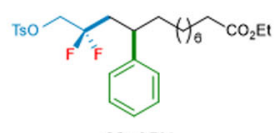

63: $35 \%$

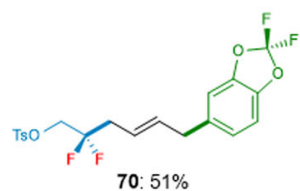

(>93:7 E.Z, r.r. > 10:1)

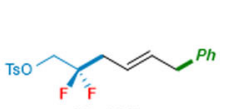

65. $98 \%$

(> 97:3 E:Z, r.r. > 11:1)

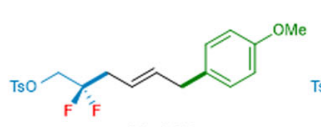

66: $63 \%$
(>97:3 E:Z, r.r. > 11:1)

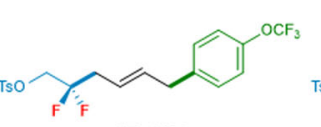

$67: 43 \%$
$(>93: 7$ E:Z, r.r. $>10: 1)$
68:57\%

(> 93:7 E:Z, r.r. > 10:1)

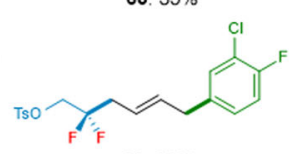

69: $69 \%$

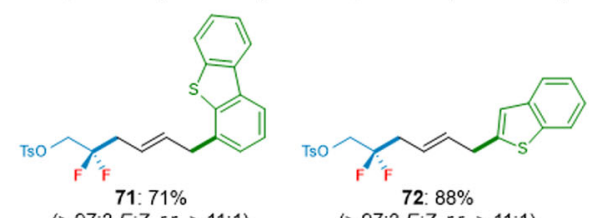

71: $71 \%$
$(>97: 3$ E:Z, r.r. $>11: 1)$

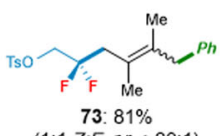

$(1: 1 Z E$, r. $>20: 1)$

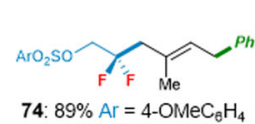

(>96:4 E:Z, r.r. = 4:1)

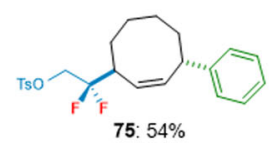

$(d r>20: 1)$

Fluoroalkylarylation of Drug Derivatives and Natural Products

(c)

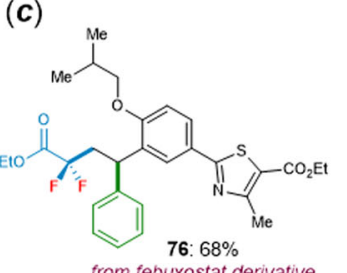

from febuxostat derivative

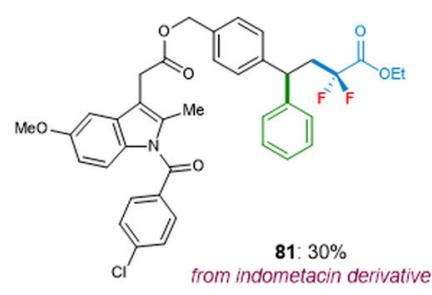

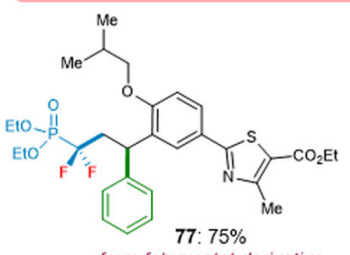

77: $75 \%$
from febuxostat derivative

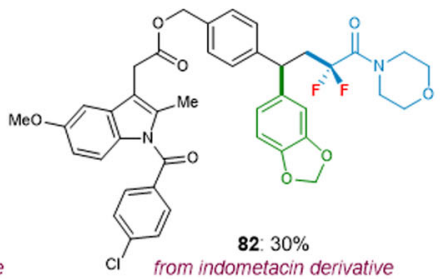

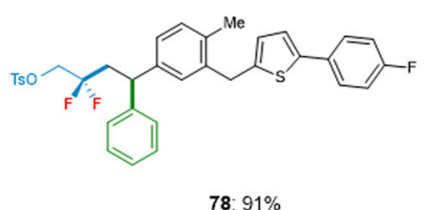

78: $91 \%$
from canagiflozin precursor

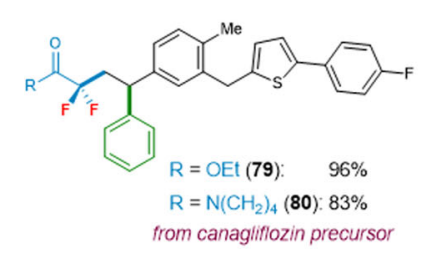

83:57\%

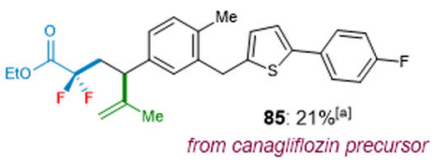

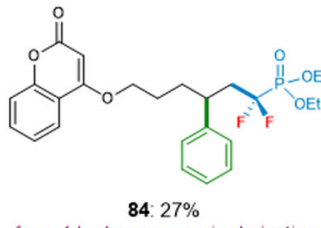

from 4-hydroxycoumarin derivative

Fig. 4 Difluoroalkylarylation of alkenes. a Scope of unactivated alkenes. b Scope of 1,3-dienes. c Late-stage difluoroalkylarylation of drug derivatives and natural products. Reaction conditions: 1k (0.25 mmol), unactivated alkenes or 1,3-dienes ( $0.5 \mathrm{mmol})$, arylzinc pivalates ( $0.5 \mathrm{mmol})$, CoBr 2 ( $10 \mathrm{~mol} \%)$, dppbz (10 mol\%), and $\mathrm{MeCN}, 23^{\circ} \mathrm{C}, 12 \mathrm{~h}$. [a] A second portion of $\mathbf{1 a}$ and isopropenylzinc pivalate was added.

methylphenylzinc pivalate was successfully employed, leading to the desired difluoroalkylarylated product 17 in $62 \%$ yield. Notably, ferrocenylzinc pivalate, as well as 3-thienylzinc pivalate also smoothly underwent the cobalt-catalyzed cascade cross-coupling, albeit yielding the products 18-19 in relatively lower yields. Thus far, electron-withdrawing groups substituted arylzinc pivalates proven to be unsuitable nucleophiles.

Thereafter, we have explored the substrate scope of the difluoroalkylarylation reaction with a wide range of vinylarenes and bromodifluoroacetate/amides (Fig. 3b). Remarkably, alkenylarenes bearing various valuable electrophilic functional groups, such as ether (22), fluoro (23), chloro (24), bromo $(25,35,37)$, trifluoromethyl (26), methyloxy (27-28, 31-32, 38-39), cyano (30), acetate (33), esters (36), and isobutyl (34) substituents, as well as vinylnaphthalene (29) and unsubstituted styrenes (20-21), were well tolerated under the reaction conditions and converted to the corresponding difluorinated 1,1-diarylalkanes in moderateto-excellent yields (40-98\%), as were also observed when using different bromodifluoroacetamides as the fluorinating reagents. Also, internal alkene with (E)- $\beta$-methylstyrene was examined under our cobalt catalysis, but only a trace amount of the desired product was detected by GC analysis (see SI). In sharp contrast, coupling of arylzinc pivalate, bromodifluoroacetate with indene gave the desired difluoroalkylarylated product $\mathbf{4 0}$ in $55 \%$ yield, with high diastereoselctivity $(d r>20: 1)$. In addition, we further investigated the cross-coupling of various fluoroalkyl bromides with olefins and arylzinc pivalates. In contrast to bromodifluoroacetate, the bromomonofluoroacetate only gave $34 \%$ yield under the standard reaction conditions, and with a poor diastereoselectivity $(d r=1: 1)$ (Fig. $3 c ; 41)$. We were also pleased to find that bromodifluoromethylphosphonate smoothly underwent the envisioned cobalt-catalyzed difluoromethylarylation to afford the desired 1,1-diarylalkylphosphonates $\mathbf{4 2 - 4 5}$ in 51-97\% yields, and compound 45 was obtained with high diastereoselectivity $(d r$ $>20: 1)$. Besides, the unactivated alkene furnished the desired difluoromethylarylated phosphonate $\mathbf{4 6}$ as well, albeit in a modest yield. Additionally, using as substrate of a-bromodifluoromethylsubstituted benzoxazole proved to be viable with versatile cobalt catalyst and, thereby, provided $\mathbf{4 7 - 4 8}$ as the products in $51-55 \%$ yields. Remarkably, this cobalt-catalyzed regioselective difluoroalkylarylation reaction was further extended to the decorated difluoroalkyl bromide. Functional groups, such as arylsulfonate, 


\section{Competition experiments}

a) intermolecular competition: $\alpha$-bromocarbonyl compounds
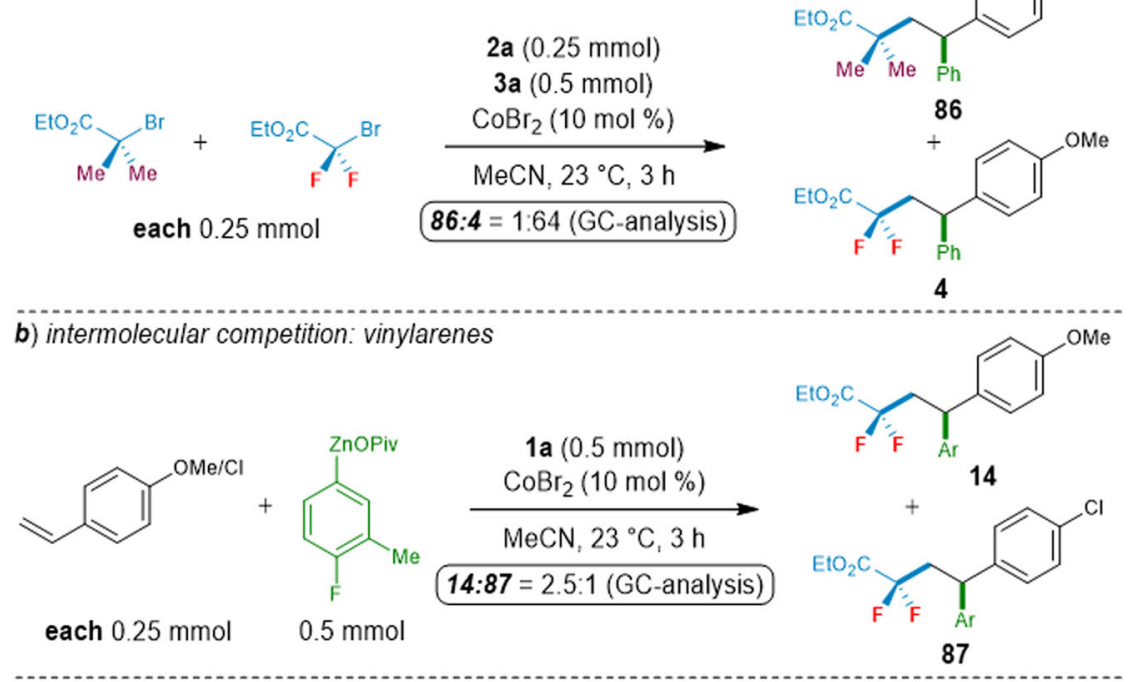

c) intermolecular competition: arylzinc pivalates
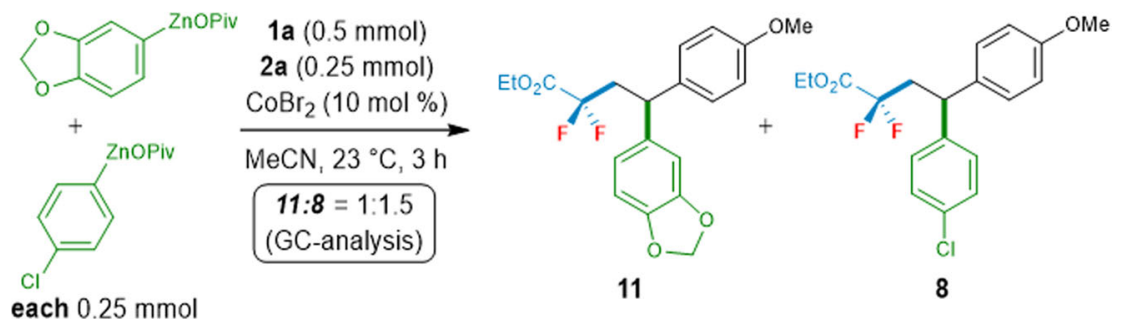

Fig. 5 Control experiments. a Competition experiments between different alkyl bromides. b Competition experiments between different vinylarenes. c Competition experiments between different arylzinc pivalates.

ester, were well tolerated under the standard reaction conditions, thus delivering the desired products $49-52$ in good yields and with high diastereoselectivity of $\mathbf{5 1}(d r>20: 1)$. To our delight, the secondary and tertiary alkyl iodides were also successfully performed for the cobalt-catalyzed alkylarylation, albeit delivering the desired products 53-56 in 24-59\% yields.

Transformations of unactivated alkenes are acknowledged widely as a challenge in transition-metal-catalyzed difunctionalization of alkenes ${ }^{49-56,69-71}$. The reaction conditions previously optimized for the alkenylarenes led to an unsatisfactorily low yield of 57, because significant amounts of a Heck-type coupling product were formed as well. However, we were delighted to find that the transformation of the unactivated alkene difluoroalkylarylation process was significantly improved when using dppbz (L9, $10 \mathrm{~mol} \%$ ) as the ligand, leading to $\mathbf{5 7}$ in 54\% yield. A number of unactivated alkenes were readily converted into the desired difluoroalkylarylated products 58-63 in moderate yields (See more details from the Supporting Information). Moreover, various synthetically valuable functional groups, including chloro, ether, and ester, remained intact by the cobalt catalyst (Fig. 4a). Beyond that, the possibility of cobalt-catalyzed difluoroalkylation to form an allyl radical, which subsequently underwent 1,3-shift and $\mathrm{Csp}^{3}-\mathrm{Csp}^{2}$ cross-couplings with arylzinc pivalates, was also investigated (Fig. 4b). Indeed, difluoroalkyl bromide $\mathbf{1 k}$ and a quite range of functionalized (hetero)aryl-zinc reagents were realized: 1,4-difunctionalization of 1,3-dienes with good regioselectivity and diastereoselectivity, thus furnishing 64-74 in 4398\% yields, albeit products $\mathbf{7 3}$ and $\mathbf{7 4}$ were obtained with 1:1 E:Z selectivity and 4:1 regioselectivity, respectively. To our delight, 1,3-octadiene was proven to be a suitable substrate as well, giving the product $\mathbf{7 5}$ with high diastereoselectivity.

To further illustrate the potential applications of this cobaltcatalyzed regioselective difluoroalkylarylation in late-stage functionalizations of pharmaceutically active molecules, alkenylarenes derivatized from (pre-)drug molecules, such as febuxostat, canagliflozin, as well as indomethacin, were well difluoroalkylarylated with arylzinc pivalates and $\alpha$-bromodifluorocarbonyl compounds or bromodifluoromethylphosphonate, leading to the corresponding products $\mathbf{7 6 - 8 2}$ in $30-96 \%$ yields. These results show the potential utility of this protocol for the discovery of bioactive drugs. Importantly, citronellol derivative was readily incorporated into the product $\mathbf{8 3}$ with remarkably high regioselectivity and chemoselectivity. Moreover, an unactivated alkene bearing a 4hydroxycoumarin proved to be a viable substrate as well, albeit delivering the phosphonate $\mathbf{8 4}$ in a rather modest yield. Finally, we showed that isopropenylzinc pivalate is well suited for the cobalt-catalyzed difluoroalkylalkenylation, although the reaction proceeded with lower yield (Fig. 4c).

Intrigued by the high regioselectivity and efficacy of our cobaltcatalyzed difluoroalkylarylation, a series of intermolecular competition experiments were performed (Fig. 5). A competition experiment between bromodifluoroacetate (1a) and 2-bromo-2methylpropanoate showed that $\mathrm{BrCF}_{2} \mathrm{CO}_{2}$ Et reacted much faster than these $\alpha$-bromocarbonyl compounds. These findings can be rationalized in terms of a prioritized direct halogen atom abstraction from difluoroalkyl bromides via single-electron transfer from a cobalt catalyst (Fig. 5a) ${ }^{81}$. Intermolecular competition experiments with different alkenylarenes and arylzinc 


\section{Mechanistic Insights}

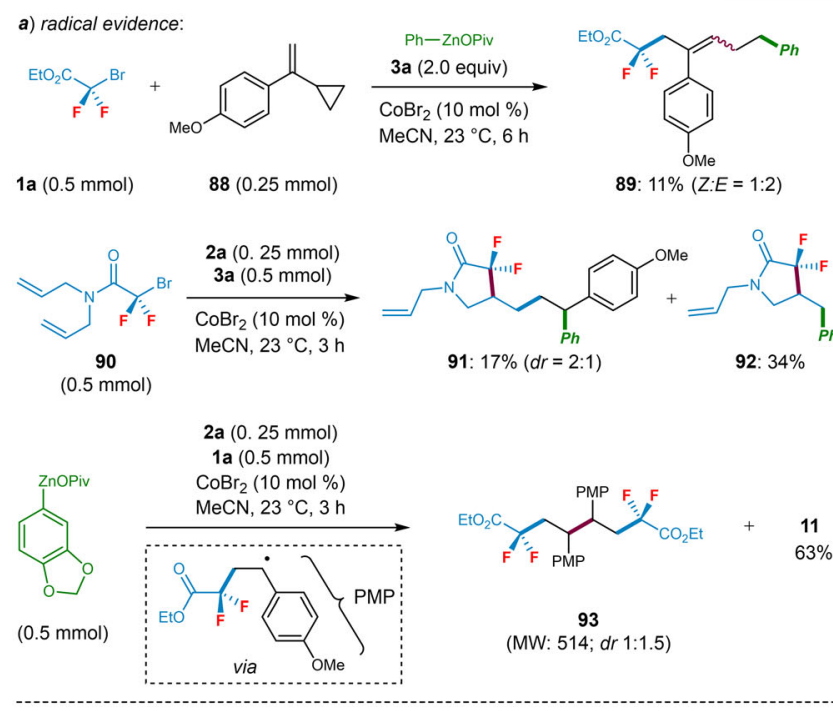

b) reduction of $\mathrm{Co}(I I)$ to $\mathrm{Co}(\mathrm{I})$ by ArZnOPiv:
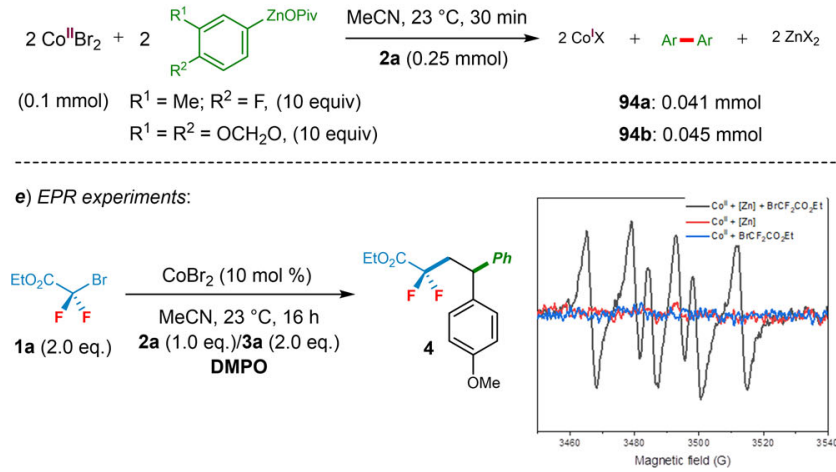

c) $\mathrm{Co}(I)$ or $\operatorname{Co}(0)$-catalyzed difluoroalkylarylation:

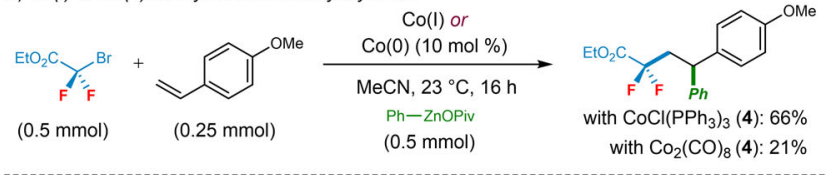

d) catalytic activity investigation of the in situ cobalt species

i) $2 \mathrm{a}(0.25 \mathrm{mmol})$

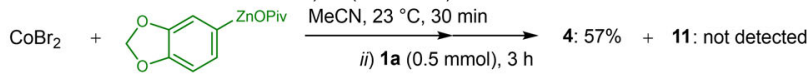

$\begin{array}{lll}(0.025 \mathrm{mmol}) & (0.05 \mathrm{mmol}) & \mathrm{Ph}-\text { ZnOPiv } \\ & & (0.5 \mathrm{mmol})\end{array}$

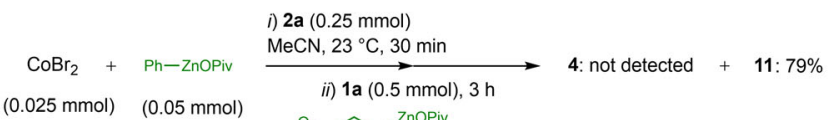

(0.025 mmol) $\quad(0.05 \mathrm{mmol})-(0.5 \mathrm{~mm}$

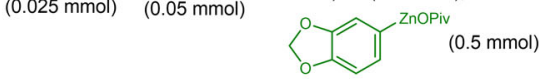

f) proposed catalytic cycle: $\quad \mathrm{CoBr}_{2}$

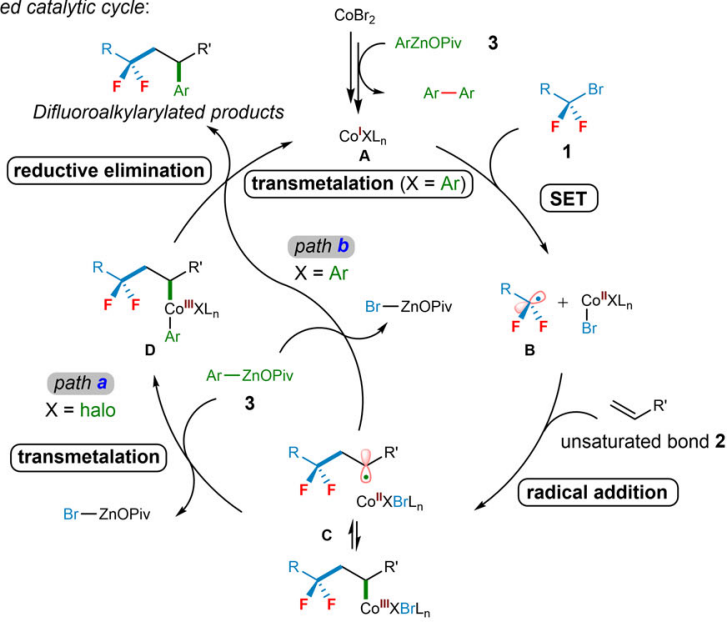

Fig. 6 Mechanistic studies for cobalt-catalyzed cascade difluoroalkylarylation. a Radical evidences. $\mathbf{b}$ Reduction of $\mathrm{CoBr}_{2}$ by arylzinc pivalates.

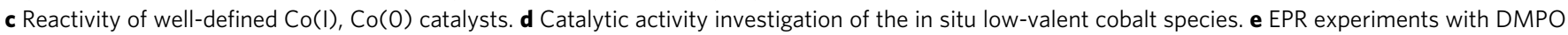
(DMPO = 5,5-dimethyl-1-pyrroline-1-oxide).

pivalates revealed electron-rich styrenes and electron-deficient arylzinc pivalates to be slightly reactive substrates (Fig. 5b, c). These results suggested that vinylarenes and arylzinc reagents might not be involved in the rate-determined step ${ }^{56}$.

Beyond that, the radical-clock experiment with substrate $\mathbf{8 8}$ bearing a radical clock cyclopropane moiety, the ring-opened difluoroalkylarylated product $\mathbf{8 9}$, was generated in $11 \%$ yield. Similarly, both three- and two-component coupling products were observed when using $N, N$-diallyl-2-bromo-2,2-difluoroacetamide (90) as a radical probe under the standard reaction conditions, the cyclized products $91(d r=2: 1)$ and 92 were generated in $17 \%$ and $34 \%$ yields, respectively. Moreover, a difluoroalkylated benzylic radical homocoupling dimer 93 was detected by GC as well. With these findings, we propose that this cobalt-catalyzed difluoroalkylarylation involves a single-electrontransfer (SET) process (Fig. 6a).

According to the earlier mechanistic studies for cobalt-catalyzed cross-coupling reactions with using organomagnesium reagents, an in situ low-valent $\mathrm{Co}(0)$ was proposed as the catalytically active species $^{52,72,73,82,83}$. On the other hand, a mechanism involving Co (I)/(III) couple was also proposed for many cobalt-catalyzed crosscouplings ${ }^{37-39,81}$. Therefore, we performed experiments of $\mathrm{CoBr}_{2}$ (1.0 equiv) with excess of ArZnOPiv under typical reaction conditions for $30 \mathrm{~min}$. These reactions furnished the corresponding homoproducts of $\mathbf{9 4 a}$ and $94 \mathbf{b}$ in near-0.5 equiv ratio to that of $\mathrm{CoBr}_{2}$, respectively. These findings support the formation of a $\mathrm{Co}(\mathrm{I})$ species based on the stoichiometry shown in Fig. 6b. In this context, the well-defined $\mathrm{Co}(\mathrm{I})$ complex, such as $\mathrm{CoCl}\left(\mathrm{PPh}_{3}\right)_{3}$ was proved to be active for the desired difluoroalkylarylated process, yielding product 4 in $66 \%$, while $\mathrm{Co}_{2}(\mathrm{CO})_{8}$ gave a poor yield (Fig. $6 \mathrm{c}$ ). Further experiments to examine the catalytic activity of the in situgenerated low-valent cobalt(I) species were performed. A mixture of vinylarene $2 \mathrm{a}(0.25 \mathrm{mmol})$ and $\mathrm{CoBr}_{2}(0.025 \mathrm{mmol})$ was treated with 2.0 equiv of 3,4-(methylenedioxy)phenylzinc pivalate $(0.05 \mathrm{mmol})$ at $23^{\circ} \mathrm{C}$ for $30 \mathrm{~min}$ to generate the proposed $\mathrm{Co}(\mathrm{I})$ species, followed by addition of bromodifluoroacetate $1 \mathbf{a}(0.3 \mathrm{mmol})$ and another 0.5 mmol of phenylzinc pivalate. The difluoroalkylarylated product 4 was isolated in $57 \%$ yield as the sole product, while the product $\mathbf{1 1}$ was obtained in $79 \%$ yield when exchanging the order of the two arylzinc reagents (Fig. 6d). These findings are consistent with the in situ-generated low-valent cobalt(I) species that might be the active catalyst for the current three-component cross-coupling reaction. A series of EPR spin-trapping experiments show the existence of $C$ centered radicals trapped by DMPO $\left(g=2.0066, \mathrm{~A}_{\mathrm{N}}=13.9 \mathrm{G}, \mathrm{A}_{\mathrm{H}}\right.$ $=19.3 \mathrm{G})$, which was considered to be $\cdot \mathrm{CF}_{2} \mathrm{R}^{84}$. These results strongly supported that the single-electron-transfer process for the activation of $\mathrm{BrCF}_{2} \mathrm{R}$ was only promoted by the in situ-formed $\mathrm{Co}(\mathrm{I})$ species (Fig. 6e). 
a) gram-scale reaction

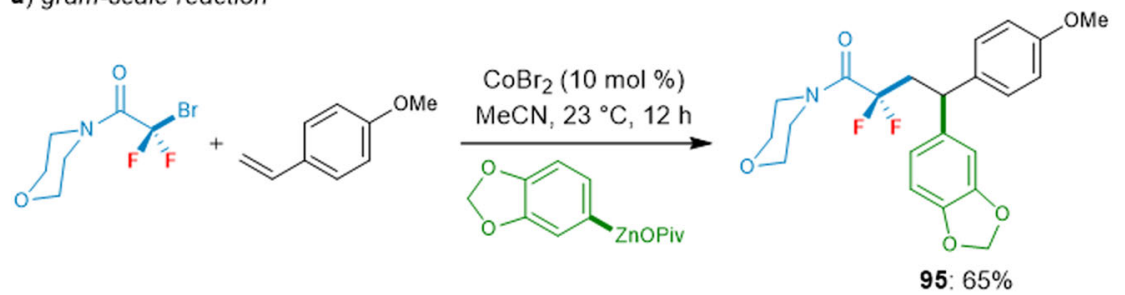

$(4.0 \mathrm{mmol}$ scale, $1.089 \mathrm{~g})$

b) modification of difluoroalkylarylated products

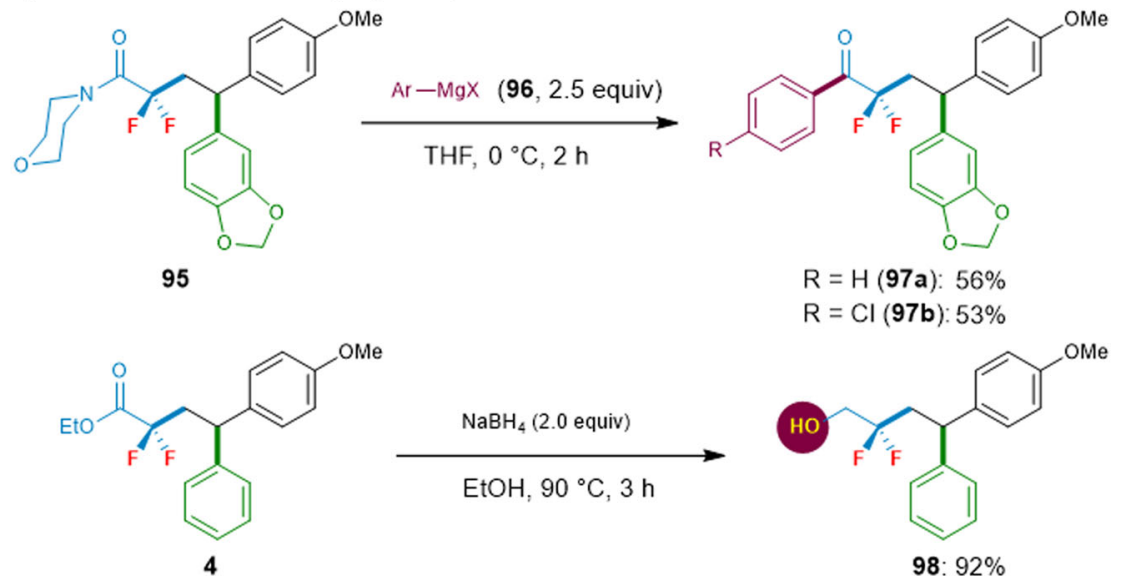

Fig. 7 Applications. a Gram-scale reaction. b Modification of difluoroalkylarylated products.

Based on the above experimental findings, along with previous mechanistic insights ${ }^{37-39,74,81}$, a mechanism for this regioselective cobalt-catalyzed difluoroalkylarylation of alkenes has been proposed as shown in Fig. 6f. The reduction of the precatalyst $\mathrm{CoBr}_{2}$ with arylzinc pivalates forms the catalytically active $\mathrm{Co}(\mathrm{I})$ species (A), which reduces difluoroalkyl bromides (1) by SET and generates difluoroalkyl radical $\mathbf{B}$, then followed by a facile radical addition of $\mathbf{B}$ into olefins (2) to afford a secondary alkyl radical species, along with subsequent rapid trapping with $\mathrm{L}_{n} \mathrm{Co}(\mathrm{II}) \mathrm{XBr}$ $(\mathrm{X}=\mathrm{Br})$ into intermediate $\mathrm{C}$, which undergoes trans-metalation with ArZnOPiv (3) to lead to the organocobalt(III) species D. Subsequent reductive elimination finally delivers the difluoroalkylarylated product and regenerates the active cobalt(I) catalyst (path a). In addition, another possible pathway is that transmetallation of arylzinc pivalates could also occur after the initial reduction step, thus in situ forming the $\mathrm{L}_{n} \mathrm{Co}(\mathrm{I}) \mathrm{X}(\mathrm{X}=\mathrm{Ar})$ species as the catalyst to promote the SET process. Radical addition and reductive elimination give rise to the desired products and regenerate the active $\mathrm{Co}(\mathrm{I})$ species (path $\mathbf{b}$ ).

We were also pleased to find that this cobalt-catalyzed difluoroalkylarylation can be easily scaled up to gram level. Under the optimized reaction conditions, the difluoroalkylarylated product 95 was afforded with high efficacy (65\% yield, Fig. 7a). Finally, we further demonstrated the synthetic potential of this cobalt-catalyzed difluoroalkylarylation strategy through the late-stage modification of the obtained difluoroalkylarylated products. For example, the resulting $\mathrm{N}$-morpholino amide $\mathbf{9 5}$ can be readily converted into various ketones by treating with Grignard reagents, thus furnishing the products $\mathbf{9 7} \mathbf{a}-\mathbf{b}$ in moderate yields. Moreover, the reduction of the ester group of substrate 4 by using $\mathrm{NaBH}_{4}$ provides the corresponding alcohol 98, which readily undergoes various derivatizations (Fig. 7b).

\section{Discussion}

In conclusion, we have reported the practical cobalt catalysis for regioselective difluoroalkylarylation of alkenes or 1,3- dienes with functionalized arylzinc pivalates and difluoroalkyl bromides. This simple cobalt catalyst enables three-component cross-couplings through cascade $\mathrm{Csp}^{3}-\mathrm{Csp}^{3} / \mathrm{Csp}^{3}-\mathrm{Csp}^{2}$ bond formation in one-pot fashion, thus generating difluoroalkylarylated products with predictable regioselectivity and high diastereoselectivity. The reaction proceeds under remarkable mild conditions with high efficacy, excellent functional group tolerance, as well as a broad substrate scope. Notable features of this approach are the use of less toxic and low-cost cobalt catalyst, as well as user-friendly solid zinc reagents. Straightforward late-stage functionalizations of pharmaceutically active molecules show the potential applications of this protocol for the discovery of bioactive drugs. Beyond that, among a series of kinetic experiments with six types of phenylzinc reagents, these solid arylzinc pivalates displayed the distinct advantage of reactivity for the current reaction. Detailed mechanistic studies demonstrated that the reaction undergoes a direct halogen atom abstraction via single-electron transfer from the in situ-formed cobalt(I) species to difluoroalkyl bromides.

\section{Methods}

Cobalt-catalyzed difluoroalkylarylation of alkenes. A suspension of $\mathrm{CoBr}_{2}(10$ mol\%), olefin ( $0.25 \mathrm{mmol}, 1.0$ equiv), difluoroalkyl bromide ( $0.5 \mathrm{mmol}, 2.0$ equiv), and aryl zinc pivalates $(0.5 \mathrm{mmol}, 2.0$ equiv) in degas $\mathrm{MeCN}(1.0 \mathrm{~mL})$ was stirred at $23^{\circ} \mathrm{C}$ for $3 \mathrm{~h}$ under an atmosphere of Ar. At ambient temperature, the solvent was evaporated under reduced pressure and the remaining residue was purified by column chromatography on silica gel to yield the desired products.

\section{Data availability}

The authors declare that all other data supporting the findings of this study, including experimental procedures and compound characterization, are available within the article and its Supplementary Information files.

Received: 26 January 2021; Accepted: 22 June 2021; Published online: 16 July 2021 


\section{References}

1. Knochel, P. (ed.) Handbook of Functionalized Organometallics: Applications in Synthesis (Wiley, 2005).

2. Miyaura, N. (ed.) Cross-Coupling reactions. A Practical Guide (Springer, 2002).

3. de Meijere, A. \& Diederich, F. (eds) Metal-Catalyzed Cross-Coupling Reactions (Wiley, 2004).

4. Hartwig, J. F. (ed.) Organotransition Metal Chemistry (University Science Books, 2010).

5. Li, J. J. \& Johnson, D. S. (eds) Modern Drug Synthesis (Wiley, 2010).

6. Boudier, A., Bromm, L. O., Lotz, M. \& Knochel, P. New applications of polyfunctional organometallics in organic synthesis. Angew. Chem. Int. Ed. 39, 4414-4435 (2000).

7. Hall, D. G. (ed.) Boronic acids. Preparation, Applications in Organic Synthesis and Medicine 2nd edn (Wiley, 2005).

8. Suzuki, A. Cross-coupling reactions of organoboranes: an easy way to construct C-C bonds (Nobel Lecture). Angew. Chem. Int. Ed. 50, 6722-6737 (2011).

9. Molander, G. A. \& Canturk, B. Organotrifluoroborates and monocoordinated Palladium complexes as catalysts-a perfect combination for Suzuki-Miyaura coupling. Angew. Chem. Int. Ed. 48, 9240-9261 (2009).

10. Miyaura, N. \& Suzuki, A. Palladium-catalyzed cross-coupling reactions of organoboron compounds. Chem. Rev. 95, 2457-2483 (1995).

11. de Meijere, A., Bräse, S. \& Oestreich, M. (eds) Metal-Catalyzed Cross-Coupling Reactions and More 3rd edn (Wiley, 2014).

12. Haas, D., Hammann, J. M., Greiner, R. \& Knochel, P. Recent developments in negishi cross-coupling reactions. ACS Catal. 6, 1540-1552 (2016).

13. Negishi, E. Magical power of transition metals: past, present, and future (Nobel Lecture). Angew. Chem. Int. Ed. 50, 6738-6764 (2011).

14. Phapale, V. B. \& Cárdenas, D. J. Nickel-catalysed negishi cross-coupling reactions: scope and mechanisms. Chem. Soc. Rev. 38, 1598-1607 (2009)

15. Knochel, P. \& Singer, R. D. Preparation and reactions of polyfunctional organozinc reagents in organic synthesis. Chem. Rev. 93, 2117-2188 (1993).

16. Hernán-Gómez, A. et al. Organozinc pivalate reagents: segregation, solubility, stabilization, and structural insights. Angew. Chem. Int. Ed. 53, 2706-2710 (2014). $\mathrm{RZnX} \cdot \mathrm{Mg}(\mathrm{OPiv})_{2} \cdot \mathrm{LiCl}$ was abbreviated as $\mathrm{RZnOPiv}$ for the sake of clarity.

17. Bernhardt, S., Manolikakes, G., Kunz, T. \& Knochel, P. Preparation of solid salt-stabilized functionalized organozinc compounds and their application to cross-coupling and carbonyl addition reactions. Angew. Chem. Int. Ed. 50, 9205-9209 (2011).

18. Manolikakes, S. M., Ellwart, M., Stathakis, C. I. \& Knochel, P. Air-stable solid aryl and heteroaryl organozinc pivalates: syntheses and applications in organic synthesis. Chem. Eur. J. 20, 12289-12297 (2014).

19. Colombe, J. R., Bernhardt, S., Stathakis, C., Buchwald, S. L. \& Knochel, P Synthesis of solid 2-pyridylzinc reagents and their application in negishi reactions. Org. Lett. 15, 5754-5757 (2013).

20. Stathakis, C. I., Manolikakes, S. M. \& Knochel, P. TMPZnOPiv•LiCl: a new base for the preparation of air-stable solid zinc pivalates of sensitive aromatics and heteroaromatics. Org. Lett. 15, 1302-1305 (2013).

21. Stathakis, C. I., Bernhardt, S., Quint, V. \& Knochel, P. Improved air-stable solid aromatic and heterocyclic zinc reagents by highly selective metalations for negishi cross-couplings. Angew. Chem. Int. Ed. 51, 9428-9432 (2012).

22. Hofmayer, M. S., Lutter, F. H., Grokenberger, L., Hammann, J. M. \& Knochel, P. Practical Ni-catalyzed cross-coupling of unsaturated zinc pivalates with unsaturated nonaflates and triflates. Org. Lett. 21, 36-39 (2019).

23. Chen, Y.-H., Tüllmann, C. P., Ellwart, M. \& Knochel, P. Preparation of solid polyfunctional alkynylzinc pivalates with enhanced air and moisture stability for organic synthesis. Angew. Chem. Int. Ed. 56, 9236-9239 (2017).

24. Tüllmann, C. P., Chen, Y.-H., Schuster, R. J. \& Knochel, P. Preparation and reactions of mono- and bis-pivaloyloxyzinc acetylides. Org. Lett. 20, 4601-4605 (2018).

25. Chen, Y.-H., Ellwart, M., Toupalas, G., Ebe, Y. \& Knochel, P. Preparation and application of solid, salt-stabilized zinc amide enolates with enhanced air and moisture stability. Angew. Chem. Int. Ed. 56, 4612-4616 (2017).

26. Greshock, T. J. et al. Synthesis of complex druglike molecules by the use of highly functionalized bench-stable organozinc reagents. Angew. Chem. Int. Ed. 55, 13714-13718 (2016).

27. Li, J. \& Knochel, P. Chromiun-catalyzed cross-couplings and related reactions. Synthesis 51, 2100-2106 (2019).

28. Piontek, A., Bisz, E. \& Szostak, M. Iron-catalyzed cross-couplings in the synthesis of pharmaceuticals: in pursuit of sustainability. Angew. Chem. Int. Ed. 57, 11116-11128 (2018).

29. Guérinot, A. \& Cossy, J. Iron-catalyzed C-C cross-couplings using organometallics. Top. Curr. Chem. 374, 1-74 (2016).

30. Tobisu, M. \& Chatani, N. Cross-couplings using aryl ethers via $\mathrm{C}-\mathrm{O}$ bond activation enabled by nickel catalysts. Acc. Chem. Res. 48, 1717-1726 (2015).

31. Bauer, I. \& Knölker, H.-J. Iron catalysis in organic synthesis. Chem. Rev. 115, 3170-3387 (2015).
32. Bedforf, R. B. How low does iron go? Chasing the active species in Fecatalyzed cross-coupling reactions. Acc. Chem. Res. 48, 1485-1493 (2015).

33. Rosen, B. M. et al. Nickel-catalyzed cross-couplings involving carbon-oxygen bonds. Chem. Rev. 111, 1346-1416 (2011).

34. Sherry, B. D. \& Fürstner, A. The promise and challenge of iron-catalyzed cross coupling. Acc. Chem. Res. 41, 1500-1511 (2008).

35. Lutter, F. H. et al. Cobalt-catalyzed cross-couplings and electrophilic aminations using organozinc pivalates. ChemCatChem 11, 5188-5197 (2019)

36. Hammann, J. M., Hofmayer, M. S., Lutter, F. H., Thomas, L. \& Knochel, P. Recent advances in cobalt-catalyzed Csp2 and Csp3 cross-couplings. Synthesis 49, 3887-3894 (2017)

37. Knappke, C. E. I. et al. Reductive cross-coupling reactions between two electrophiles. Chemistry 20, 6828-6842 (2014).

38. Cahiez, G. \& Moyeux, A. Cobalt-catalyzed cross-coupling reactions. Chem Rev. 110, 1435-1462 (2010).

39. Gosmini, C., Begouin, J.-M. \& Moncomble, A. Cobalt-catalyzed crosscoupling reactions. Chem. Commun. 44, 3221-3233 (2008).

40. Hammann, J. M., Lutter, F. H., Haas, D. \& Knochel, P. A robust and broadly applicable cobalt-catalyzed cross-coupling of functionalized bench-stable organozinc pivalates with unsaturated halides. Angew. Chem. Int. Ed. 56, 1082-1086 (2017)

41. Li, J. \& Knochel, P. Cobalt-catalyzed cross-couplings between alkenyl acetates and aryl or alkenyl zinc pivalates. Angew. Chem. Int. Ed. 57, 11436-11440 (2018).

42. Chen, Y. H., Grassl, S. \& Knochel, P. Cobalt-catalyzed electrophilic amination of aryl- and heteroarylzinc pivalates with N-hydroxylamine benzoates. Angew. Chem. Int. Ed. 57, 1108-1111 (2018).

43. Li, J. et al. Cobalt-catalyzed electrophilic aminations with anthranils: an expedient route to condensed quinolines. J. Am. Chem. Soc. 141, 98-103 (2019).

44. Liu, X.-G. et al. Decarboxylative negishi coupling of redox-active aliphatic esters by cobalt catalysis. Angew. Chem. Int. Ed. 57, 13096-13100 (2018).

45. Lutter, F. H., Grokenberger, L., Hofmayer, M. S. \& Knochel, P. Cobaltcatalyzed acylation-reactions of (hetero)arylzinc pivalates with thiopyridyl ester derivatives. Chem. Sci. 10, 8241-8245 (2019).

46. Yin, G., Mu, X. \& Liu, G. Palladium (II)-catalyzed oxidative difunctionalization of alkenes: bond forming at a high-valent palladium center. Acc. Chem. Res. 49, 2413-2423 (2016).

47. McDonald, R. I., Liu, G. \& Stahl, S. S. Palladium(II)-catalyzed alkene functionalization via nucleopalladation: stereochemical pathways and enantioselective catalytic applications. Chem. Rev. 111, 2981-3019 (2011).

48. Beller, M., Seayad, J., Tillack, A. \& Jiao, H. Catalytic markovnikov and antimarkovnikov functionalization of alkenes and alkynes: recent developments and trends. Angew. Chem. Int. Ed. 43, 3368-3398 (2004)

49. Orlandi, M., Hilton, M. J., Yamamoto, E., Toste, F. D. \& Sigman, M. S. Mechanistic investigations of the $\mathrm{Pd}(0)$-catalyzed enantioselective 1,1diarylation of benzyl acrylates. J. Am. Chem. Soc. 139, 12688-12695 (2017).

50. Saini, V. \& Sigman, M. S. Palladium-catalyzed 1,1-difunctionalization of ethylene. J. Am. Chem. Soc. 134, 11372-11375 (2012).

51. Werner, E. W., Urkalan, K. B. \& Sigman, M. S. PdII-catalyzed oxidative 1,1diarylation of terminal olefins. Org. Lett. 12, 2848-2851 (2010).

52. Ikeda, Y., Nakamura, T., Yorimitsu, H. \& Oshima, K. Cobalt-catalyzed Hecktype reaction of alkyl halides with styrene. J. Am. Chem. Soc. 124, 6514-6515 (2002).

53. Qin, T. et al. A general alkyl-alkyl cross-coupling enabled by redox-active esters and alkylzinc reagents. Science 352, 801-805 (2016).

54. Zhang, L. et al. Catalytic conjunctive cross-couplingenabled by metalinducedmetallate rearrangement. Science 351, 70-74 (2016).

55. Kischkewitz, M., Okamoto, K., Mück-Lichtenfeld, C. \& Studer, A. Radicalpolar crossover reactions of vinylboron ate complexes. Science 355, 936-938 (2017).

56. $\mathrm{Kc}$, S. et al. Ni-catalyzed regioselective alkylarylation of vinylarenes via $\mathrm{C}(\mathrm{sp} 3)$ $-\mathrm{C}(\mathrm{sp} 3) / \mathrm{C}(\mathrm{sp} 3)-\mathrm{C}(\mathrm{sp} 2)$ bond formation and mechanistic studies. J. Am. Chem. Soc. 140, 9801-9805 (2018).

57. Kc, S., Dhungana, R. K., Khanal, N. \& Giri, R. Nickel-catalyzed acarbonylalkylarylation of vinylarenes: expedient access to $\gamma, \gamma$-diarylcarbonyl and aryltetralone derivatives. Angew. Chem. Int. Ed. 59, 8047-8051 (2020).

58. Link, J. O. et al. Discovery of ledipasvir (GS-5885): a potent, once-daily oral NS5A inhibitor for the treatment of hepatitis C virus infection. J. Med. Chem. 57, 2033-2046 (2014)

59. Begue, J. P. \& Bonnet-Delpon, D. Bioorganic and Medicinal Chemistry of Fluorine (Wiley, 2008).

60. Purser, S., Moore, P. R., Swallow, S. \& Gouverneur, V. Fluorine in medicinal chemistry. Chem. Soc. Rev. 37, 320-330 (2008).

61. O'Hagan, D. Understanding organofluorine chemistry. introduction C. $-F$. bond. Chem. Soc. Rev. 37, 308-319 (2008).

62. Muller, K., Faeh, C. \& Diederich, F. Fluorine in pharmaceuticals: looking beyond intuition. Science 317, 1881-1886 (2007). 
63. Mikami, K., Itoh, Y. \& Yamanaka, M. Fluorinated carbonyl and olefinic compounds: basic character and asymmetric catalytic reactions. Chem. Rev. 104, 1-16 (2004)

64. Feng, Z., Xiao, Y.-L. \& Zhang, X. Transition-metal (Cu, Pd, Ni)-catalyzed difluoroalkylation via cross-coupling with difluoroalkyl halides. Acc. Chem. Res. 51, 2264-2278 (2018).

65. Li, C. et al. Cobalt-catalyzed difluoroalkylation of tertiary aryl ketones for facile synthesis of quaternary alkyl difluorides. Nat. Commun. 9, 4951-4957 (2018).

66. Belhomme, M.-C., Besset, T., Poisson, T. \& Pannecoucke, X. Recent progress toward the introduction of functionalized difluoromethylated building blocks onto C(sp2) and C(sp) centers. Chemistry 21, 12836-12865 (2015).

67. Yang, X., Wu, T., Phipps, R. J. \& Toste, F. D. Advances in catalytic enantioselective fluorination, mono-, di-, and trifluoromethylation, and trifluoromethylthiolation reactions. Chem. Rev. 115, 826-870 (2015).

68. Liang, T., Neumann, C. N. \& Ritter, T. Introduction of fluorine and fluorinecontaining functional groups. Angew. Chem. Int. Ed. 52, 8214-8264 (2013).

69. Gu, J.-W., Min, Q.-Q., Yu, L.-C. \& Zhang, Z. Tandem

difluoroalkylationarylation of enamides catalyzed by nickel. Angew. Chem. Int. Ed. 55, 12270-12274 (2016).

70. Xu, C., Yang, Z.-F., An, L. \& Zhang, X. Nickel-catalyzed difluoroalkylationalkylation of enamides. ACS Catal. 9, 8224-8229 (2019).

71. Xu, C., Cheng, R., Luo, Y.-C., Wang, M.-K. \& Zhang, X. trans-Selective aryldifluoroalkylation of endocyclic enecarbamates and enamides via nickel catalysis. Angew. Chem. Int. Ed. 59, 18741-18747 (2020).

72. Mizutani, K., Shinokubo, H. \& Oshima, K. Cobalt-catalyzed three-component coupling reaction of alkyl halides, 1,3-dienes, and trimethylsilylmethylmagnesium chloride. Org. Lett. 5, 3959-3961 (2003).

73. Lv, X.-L., Wang, C., Wang, Q.-L. \& Shu, W. Rapid synthesis of $\gamma$-arylated carbonyls enabled by the merge of copper- and photocatalytic radical relay alkylarylation of alkenes. Org. Lett. 21, 56-59 (2019).

74. Han, S., Liu, S., Liu, L., Ackermann, L. \& Li, J. Cobalt-catalyzed diastereoselective difluoroalkylation/Giese addition domino reactions. Org Lett. 21, 5387-5391 (2019)

75. Da, Y. et al. Copper(I)-catalyzed difluoroalkylation of alkenes: a route to functionalization of lactones. Org. Lett. 20, 5149-5152 (2018).

76. Li, J., Jin, L., Liu, C. \& Lei, A. Quantitative kinetic investigation on transmetalation of ArZnX in a Pd-catalysed oxidative coupling. Chem. Commun. 49, 9615-9617 (2013).

77. Jin, L., Xin, J., Huang, Z., He, J. \& Lei, A. Transmetalation is the rate-limiting step: quantitative kinetic investigation of nickel-catalyzed oxidative coupling of arylzinc reagents. J. Am. Chem. Soc. 132, 9607-9609 (2010).

78. Jin, L. et al. Revelation of the difference between arylzinc reagents prepared from aryl Grignard and aryllithium reagents respectively: Kinetic and structural features. J. Am. Chem. Soc. 131, 16656-16657 (2009).

79. Zhang, G. et al. Structure-kinetic relationship study of organozinc reagents Chem. Commun. 50, 8709-8711 (2014).

80. Piller, F. M., Appukkuttan, P., Gavryushin, A., Helm, M. \& Knochel, P. Convenient preparation of polyfunctional aryl magnesium reagents by a direct magnesium insertion in the presence of LiCl. Angew. Chem. Int. Ed. 47, 6802-6806 (2008).

81. Wu, G. \& von Wangelin, A. J. Stereoselective cobalt catalyzed halofluoroalkylation of alkynes. Chem. Sci. 9, 1795-1802 (2018).

82. Ohmiya, H., Yorimitsu, H. \& Oshima, K. Co-mediated synthesis of alkenyl and alkynyl silanes from alkyl halides. Org. Lett. 8, 3093-3096 (2006).
83. Ikeda, Y., Yorimitsu, H., Shinokubo, H. \& Oshima, K. Cobalt-Mediated Mizoroki-Heck-type reaction of epoxide with styrene. Adv. Synth. Catal. 346, 1631-1634 (2004)

84. Fan, W.-T., Li, Y., Wang, D., Ji, S.-J. \& Zhao, Y. Iron-catalyzed highly paraselective difluoromethylation of arenes. J. Am. Chem. Soc. 142, 20524-20530 (2020).

\section{Acknowledgements}

We thank the National Natural Science Foundation of China (21602083) and Start-up Grant of Soochow University (GJ10900220) for financial support. We are grateful to Prof. Yi-hung Chen for their kind discussions, and Jianlin Yao, and Chen Zhu for their kind support and accessing to the laboratory.

\section{Author contributions}

X. C., X. L., and S. W. contributed equally to this work and they planned, conducted, and analyzed the experiments. X. C., X. L., S. W., Y. H., and B. H. performed the experiments. J. L., and A. L. designed and directed the project and wrote the paper with contributions from all coworkers.

\section{Competing interests}

The authors declare no competing interests.

\section{Additional information}

Supplementary information The online version contains supplementary material available at https://doi.org/10.1038/s41467-021-24596-6.

Correspondence and requests for materials should be addressed to A.L. or J.L.

Peer review information Nature Communications thanks the anonymous reviewer(s) for their contribution to the peer review of this work. Peer reviewer reports are available.

Reprints and permission information is available at http://www.nature.com/reprints

Publisher's note Springer Nature remains neutral with regard to jurisdictional claims in published maps and institutional affiliations.

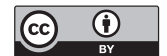

Open Access This article is licensed under a Creative Commons Attribution 4.0 International License, which permits use, sharing, adaptation, distribution and reproduction in any medium or format, as long as you give appropriate credit to the original author(s) and the source, provide a link to the Creative Commons license, and indicate if changes were made. The images or other third party material in this article are included in the article's Creative Commons license, unless indicated otherwise in a credit line to the material. If material is not included in the article's Creative Commons license and your intended use is not permitted by statutory regulation or exceeds the permitted use, you will need to obtain permission directly from the copyright holder. To view a copy of this license, visit http://creativecommons.org/ licenses/by/4.0/.

(c) The Author(s) 2021 